SOCIAL RESEARCH REPORTS

ISSN: 2066-6861 (print), ISSN: 2067-5941 (electronic)

\title{
MOTHER'S PARENTING STYLE AND ITS IMPACT ON THE DEVELOPMENT OF AVOIDANT PERSONALITY DISORDER AMONG ISRAELI CHILDREN
}

\author{
Lotem KAROLINSKY
}

Social Research Reports, 2019, Vol. 11, Issue 2, pp. 9-19

The online version of this article can be found at:

www. researchreports.ro

\section{https://doi.org/10.33788/srr11.2.1}

Published by:

Expert Projects Publishing House

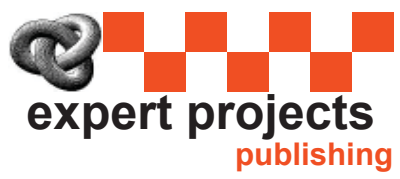

Covered by Index Copernicus International www.indexcopernicus.com

Directory of Open Access Journals www.doaj.org

On behalf of:

Center for Program and Social Development

Aditional services and information about Social Research Reports can be found at: www.researchreports.ro 


\title{
MOTHER'S PARENTING STYLE AND \\ ITS IMPACT ON THE DEVELOPMENT OF AVOIDANT PERSONALITY DISORDER AMONG ISRAELI CHILDREN
}

\author{
Lotem KAROLINSKY ${ }^{1}$
}

\begin{abstract}
This study examines a mother's parenting style and in particular her neglect of her child as risk factors for the development of avoidant personality disorders among Israeli school children aged 11-12. The findings of this study are based on qualitative, comparative research where two groups, each comprised of five Israeli mothers of children in the same age range and from the same school, were thoroughly interviewed about their parenting style. One group comprised mothers of regular children and the other of children who suffer from avoidant personality disorder. The findings of this research lead to the conclusion that parental neglect constitutes a significant factor contributing to the development of the avoidant personality disorder.
\end{abstract}

Keywords: avoidance personality disorder, parenting style, parental neglect, childhood.

\section{Introduction}

This study examines the connection between the parental practice of neglect and the social avoidant disorder among their children. More specifically, the study examines the impact of the independent variable of the mother's practices of neglect and her parenting style of being Indifferent on the development of the social avoidant disorder among her child. Based on previous studies, motherly behavior affects social anxiety of the children more than fatherly behavior (Joyce et al., 2003).

The avoidant disorder depicts an individual who has in general a low level of self-confidence and fears being mocked by others. S/he is also sensitive to the feeling of dissatisfaction of him/herself by others (Holt, Heimberg, \& Hope, 1992; Turner, Beidel, and Townsley, 1992). Subsequently an avoidant individual usually seeks to limit contacts with other people. Also, such an individual may refrain from being conspicuous or standing at the center of attention, given that such situations raise his/her anxiety. Such children find it difficult initiating

${ }^{1}$ West University of Timisoara, Timisoara, Romania. Email: lotemm@gmail.com 
friendship contacts with their peers and are often considered to be introvert and shy persons. In addition, they may suffer from social anxiety accompanied by a feeling of discomfort in situations that require contacts with others, which can lead them to keep distance and avoid social contacts. At the school level, despite their knowledge, they may not participate in class discussions. Further, they tend to avoid taking part in class parties and may reduce their involvement in school events to a minimum. As a result of this social loneliness, avoidants usually suffer from depression. The social avoidance disorder is accompanied by body symptoms like accelerated pulse, shying, sweating and shaking in the body and in the voice, while the problem may worsen without adequate treatment (Ollendick $\&$ Grills, 2016). Their close colleagues define them as introverted, sensitive and shy, but their situation is much more complex. In fact, such children are anxious to overcome their social isolation, but they hesitate initiating social connections for fear that they will be scorned by others. Hence, they refrain from countering their anxiety and as a result they experience farther frustration and despair due the absence of experience in acquiring social skills (Muris \& Ollendick, 2015). Finally, avoidant individuals according to many studies usually shy away from asking for help (Schneier et al., 2011; Kashdan et al., 2014) and seek social relations only when they are certain that the other person likes them.

\section{Types of Avoidant Personalities}

Persons who are diagnosed with the social avoidant disorder are normally portrayed as both longing for and having anxiety of close connections with other people (Bögels et al., 2010). In other words, avoidants are portrayed as fearful of social relationship combined with a tendency of developing a personality of being independent. It is possible to recognize two types of avoidant personalities. First is "fearful avoidants" who have negative views of both their self as well as of other people; subsequently they both want but are afraid of social closeness. Second is "rejecting avoidants" who have a positive view of oneself however a negative view of others. In general, an avoidant figure appears to be excessively sensitive and low in self-confidence (Holt, Heimberg, \& Hope, 1992). Some scholars of this subject reveal that the two contrasted sorts of avoidants are not surprising. Although the two types of avoidants distinguish themselves as "socially avoidant," fearful avoidants have lower self-confidence, in general, than "rejecting avoidants," who have a positive view of themselves and thus have a higher self-confidence. Also, in view of self and others, rejecting avoidants seem to be cold, and are depicted as aggressive, despotic, and contemplative. Fearful avoidants, conversely, seem to be agreeable, and are portrayed by themselves as well as by others as low-confident, independent and exploitable. Obviously, fearful avoidants are more likely than the other types of persons with social disorder to report having grown up with issue of alcoholic parents (Brennan \& Shaver, 1998). 
As anticipated, rejecting avoidants characterize themselves as secure, demonstrating some protectiveness. Several studies contrast persons diagnosed of being socially avoidants with a random sample of undergraduate students and discover a proof pointing to a connection with other related distresses, such as anxiety, separating in protest, furious withdrawal, in addition to being ambivalent and inclining to avoid sentimental and/or sexual relationship.

Essentially, rejecting avoidants, similar to fearful avoidants, seem to want intimate friendship with others yet always have the anxiety of being rejected. As a result, these people are most likely tend to maintain a strategic distance from social associations that would otherwise assuage their social isolation. Most alarming is that the two sorts of avoidant people may counter sentiments of depression by drinking alcohol, using drugs or unsafe sexual intercourse, thus aggravating their social relational challenges with more problems. Rejecting avoidants, in addition, who portray themselves as unsociable and seem to ridicule the significance of friendship relationship, are probably going to be schizoid (a personality disorder that characterized a person of being disinterested in social relationship and seeks solitary, and is emotionally cold etc.). That is, both rejecting and fearful avoidant persons are more likely to embrace being independent and avoid friendship connections. Some scholars reveal a relationship between the schizoid phenomena and the intimacy-related element of obsessive self-sufficiency. This affiliation is the thing that one would expect if a rejecting (to a less extent fearful) avoidant is most intently connected with the schizoid behavior.

\section{Parenting styles and parental practices}

Parents usually comprise the first and main circle in their children's life; they are the ones who acknowledge and compensate the child's accomplishments. Hence, their impact on the psychological wellness and conduct of the kid, both in providing support and mounting the burden of pressures and tension, is noteworthy (Hudson and Rapee, 2001). Scientists distinguish two focal points in parental conduct that allow psychologists to diagnose the child's personality and her/his social attributes. First is the component of warmth and support, articulating parental routine with regards to appreciation, acknowledging and acceptance. These practices point to a positive affection in the parental disposition. This positive affection is contrasted with a parental conduct of neglect, disregard, and dismissal. The second component includes control and supervision by the parents, articulating a parental approach to the degree of autonomy of the child, rather than domination. This second practice is associated with setting rules and limits, whose purpose are to discipline the child, while giving a clarification and reasoning for their practices to the child in parallel to consolidating his/her ability to be autonomous and make decisions within the limits that were set by the parents. By the same token, coercive parental domination of the child's behaviour most likely will harm the development of the kid's autonomous personality (Moore, Whaley, \& Sigman, 2004). This practice instill in the kid's mind that $\mathrm{s} /$ he must satisfy the expectations of his/her 
parents in order to receive his/her parental love and backing, where the kid does not make decisions on what seems right or wrong to him/her, but on what is right from the point of view of his/her parents (Hudson \& Rapee, 2001).

Furthermore, overprotective and/or domination parenting style creates a major impact on the shyness and lack of self-confidence characteristics of the children (Moore, Whaley, \& Sigman, 2004).

Moreover, mothers, who suffer from anxiety, are more likely to create unhealthy parental connections with their child, which may cause to the development of anxiety among the child and avoidance behavior already in kindergarten. Such children tend to express insecure attachment with the mother articulated through a tendency of the child to keep distance from her/his parents (Herren, In-Albon, \& Schneider, 2013).

Models of parenting styles combine various types of parental disciplining styles and support on a spectrum where on the one end there is the reactive-emotional practice and on the other end the demanding practice (Hughes et al., 2005). The reactive-emotional practice points to the extent to which the parent endeavors to meet the requests and desires of the child in a supportive way. The parent interacts with the child in sensitive and adaptive manner appropriate to the child's requests and needs. The demanding dimension, by contrast, reflects the extent to which the parent anticipates accountability and disciplined behavior by the child. This practice includes setting rules and limits on the child's behavior. From a spectrum of the above two practices emerge four parenting styles that forge the personality and emotional development of the child.

Hence, studies on children development distinguish four various parenting styles (Cramer, 2011). First is the Authoritarian/Autocratic parent, who attempts to shape, control and assess the conduct of the child according to a pre-given set of rules. Compliance with the rules is usually observed by the parent; the child is anticipated to follow the parent's orders without questioning. Disciplinary measures are implemented in order to realize obedience, otherwise the parent implement punitive measures including physical violence in case of disobedience or incompliance. Based on this sort of parenting style, the parent is assertive but not responsive to child's needs and desires. Second, is the Authoritative/Responsive parent, who gives clear rules to the kid's behaviour, and uses discussion and clarification to discipline the child's practices. These parents are assertive but not invasive. They take into account the kid's perspective, and expect that the kid has rights. Order is desirable for the best interest of the child and the goal of disciplining the child is not to punish him/her. This sort of parenting style is both assertive and responsive. Third is the Indulgent parenting style, where the parent articulates warmth, emotions and tolerance and thinks that it is hard to penalize the child, while the parent does not expect mature conduct. This parent is responsive to the child's requests and needs and at the same time not assertive. Fourth is the Indifferent parenting style, where the parent is uninvolved and neither assertive nor responsive. S/he anticipates that the child should deal with issues alone, urges the kid to be autonomous of the parent without the latter's support and anticipates that the child should assume accountability for his/her own affairs. This fourth parenting style of Indifferent is most relevant to this study of examining parent's practices of neglect and the child's social avoidant disorder. 
Researches demonstrate that the authoritative/responsive parenting style, when contrasted with the other three styles, is associated to a high extent with a normative behaviour of the child (Rossman and Rea, 2005). A positive relationship is found in the association between the authoritative style and social capacities, more than the other three parenting styles (Martínez \& García, 2007).Teenagers who gave an account of invasive and strict supervision, as portrayed in an authoritarian parenting style, articulate numerous side effects of hardship, depression and conduct issues in contrast with teenagers who encountered an authoritative parenting style (Fletcher et al., 2008). It is conceivable to state that while the authoritative parenting style empowers the child to construct self-confidence and high self-esteem and typical social behaviour, while an authoritarian parenting style depresses the self-esteem of the child, and decreases his/her self-confidence (Martínez \& García, 2007). In contrast, the indulgent parenting style, creates maximum leeway for the child and stands in opposite to the authoritarian parenting style that blocks the child from making strides required for coping with challenges and real problems which are expected outside the family framework (Cramer, 2011).These practices can impact emphatically or adversely the advancement of the child's capacities in different psychological issues, among them social wellness in contrast with social anxiety and avoidance

In short, parental support and their appreciation are crucial components in shaping a child's personality during his/her childhood and teenage periods. The significance of parental practice of empowering the child are articulated via allowing him/her to feel comfortable with the company of the parent and by convincing the kid that $\mathrm{s} / \mathrm{he}$ is accepted as an individual by the parent (Martínez \& García, 2007). Because of this, the authoritarian parenting style is seen as an invalid style in western societies (Cramer, 2011).

Furthermore, the Parent-Friend Scale comprises of measurements estimating participants' apparent nature of treatment by each of the parents and friends while growing up. This parental measurements incorporate: (1) appreciation versus dismissal (e.g., "my parent gave me the feeling that he/she accepts me as I seemed to be, and didn't need to transform me into another person") (2) cultivating autonomy versus over-protective (e.g., my parent urged me to get things done by myself"); and (3) cautious admiration (e.g., "my parent had not even one blame that I can consider"). In a test conducted by one study, participants got some information about their moms, and afterwards about their dads, for an aggregate of six scales (Brennan and Shaver 1998). In this study, the three mother scales had coefficient alphas of .87 (appreciation/dismissal), .82 (autonomy/over-protectiveness), and .88 (admiration). The three dad scales had coefficient alphas of .89 (appreciation/ dismissal), .79 (autonomy/over-protectiveness), and .92 (admiration).

Likewise, the Schizoid scale, as mentioned above, estimates an individual's inclination to withdraw from others, along the lines of separating oneself from associations with parents, siblings and peers (Brennan and Shaver, 1998). One thing on this scale is "Others consider me to be cold and dispassionate." The Schizoid scale depicts people who have encountered a break from the real world (Turner, Beidel, \& Townsley, 1992). These people may trust that they are getting subliminal messages from others. A typical statement by them includes: "I have a surprising capacity to realize that things will occur before they really do." In this regard, 
the Avoidant scale depicts an individual who in general lacks self-confidence and fears being disparaged by or objected by others. Along these lines the avoidant individual likes to limit contact with others. A model is "I make companions with individuals just when I am certain that they like me."

The overall extent of each disorder was typically frequently higher than its recurrence in the overall sample of this study. For instance, the two sorts of avoidants were considerably more liable to be determined as Schizoid; fearful individuals were especially prone to be analyzed with the Avoidant disorder. To assess children, who encounter (neglect and abuse) as factors causing for avoidant in depressed persons (Joyce et al., 2003); the results point to the fact that avoidant disorder can be conceived as emerging from a mixture of harm avoidance (shyness, fear), youth anxiety disorder and parental neglect. Avoidant disorder can be defined as emerging from a mixture of childhood mistreatment as well as neglect. In other words, the combinations of negative factors from the spheres of temperament and childhood psychopathology cause to the evolvement of the avoidant disorder.

\section{Methodology}

This work is an exclusively comparative, qualitative research examining the effect of my independent variable of Parental Neglect on my dependent variable of Social Avoidant Disorder among their children aged 11-12. I conducted long personal interviews, where purposive questions were presented to a group of ten Israeli mothers divided into two numerically equal groups. The participants' responses were deeply and qualitatively compared and assessed for examining the relationship between the two variables. Participants: 10 mothers who live in the city of Haifa, Israel, of medium-low socio-economic status, where five selected mothers are of children with social avoidance disorder and five mothers of regular, average children. The selected children are pupils of 5th -6th grades, age: 11-12 years old. These children were selected with close consultation with the class educator and counselor in the school using the following tools.

Tool I: Educators and the Counselors classified the average pupils and the pupils with social avoidance disorder. The criteria of singling out an average pupil are based on the definition of Hawely, according whom, regular average children in the classroom have partial social influence on others, they are not central members of the group and are not rejected by their colleagues (Hawley, 1999). By contrast, the criteria of pupils with social avoidance disorder are based on DSM-V (2013): avoidance from social situations (reluctance to come to class-parties, trips, or participating in the school social events or ceremonies, etc.), seclusion (during the breaks and at home in the afternoon based to reports of the parents to the educator and the counselor), shake/silence or excessive blushing while speaking, fear to come to school because of the need to staying with other pupils, fear to eat in the class, and low self-esteem (American-Psychiatric-Association, 2013).

Tool II: Examining of the Parenting Practices: Clinical parenting semi-structured interview was conducted in order to examine the parenting practices (parenting style) (Mayseless \& Scharf, 2003). The practices that were examined throughout 
the interview include: Acceptance/warmth versus rejection, Emotional regulation, Discipline style, Encouraging autonomy versus overprotection, Achievements and the perception of the mother of her child's social abilities.

In addition, the mothers interview was clinical parenting semi-structured interview that served to examine the parenting practices (parenting style) - Parenting Adolescents Interview.

The empirical sample of population selected is too small for making sweeping general theoretical statements and to come out with crystal-clear conclusions about the connection between the two variables. This can be taken as a shortcoming of this study, but at the same time it constitutes an advantage, given that the interviews were conducted in depth and the mothers were able to express their opinions and their feelings and bring to the fore their own invaluable experience, while commenting freely about their disappointments and frustration of raising a child that suffers from the social avoidant disorder and their implicit or explicit responsibility for this outcome. Along with the array of collected evidence about the connection between the two variables, these make the quality and this research significant.

\section{Hypotheses:}

H0: The neglect practices of mothers are a crucial factor that affects the social avoidance disorder of their children.

H1: The neglect practices of mothers are a minor factor that may affect social avoidance disorder of their children.

\section{Findings}

An analysis of the findings show clear-cut differences between mothers of socially avoidant children and mothers to regular average children on the subsequent parental practices: the first scrutiny of the interview was to examine the issue of acceptance versus rejection, and the evidence indicates that mothers of regular children seem to perceive the relationship more positively and warmly, use a variety of emotional expressions, which are appropriate to the situation. Mothers of avoidant children tend to exaggerate their emotional expressions toward their child by physical contact. Material gift-buying was also found to occur more frequently among mothers of children who are socially avoidants than among mothers of regular children, whose emotional expressions were found to be more common, such as: joint activities. In the literature it is specified that acceptance / warmth is expressed in the authoritative parenting style, which is characterized by supportive behavior and positively affects the child's emotional and social development. Another evidence indicates that a positive connection was found between the authoritative style and a high level of social competence.

The second scrutiny aimed at examining emotional regulations; the finding indicates that mothers of regular children show different responses when the child expresses feelings, such as sadness, fear or pain. These mothers expressed solidarity with the child when s/he was sad, frightened or felt painful and they initiated a conversation to clarify the child's well-being and the reason for his/her 
agony, allowing personal space and time for his/her relaxation, while proposing ways to cope with the problem, addressing medical treatment and giving attention in appropriate measure, such as physical contacts and spending time doing join activities. Mothers of avoidant children, in contrast, were questioning their child for more details, not allowing personal space, and they expressed a need to protect him and be beside him - not trusting the child's ability to cope with his/her agony by him/her-self. In a state of fear, the mother negates the child's feelings and verbally calms him: "It will be all right". In a painful situation, they expressed a high degree of physical closeness to the point of holding hands in public. Previous researches show that children characterized by an insecure attachment pattern due to overly protective maternal behavior tend to develop social anxiety.

The third scrutiny examined the terms of the mothers' understanding of their child. It was found that mothers of regular children expressed their sadness or joy by body language or a direct eye contact with their child. Mothers of avoidant children indicated that they understand their child to a great extent, especially when $\mathrm{s} /$ he experiences negative emotions. This finding may be due to the need of mothers to protect their child mainly when s/he needs support.

The forth scrutiny aimed at examining the parenting style practiced by the mother to discipline the child. Based on my interviews, I came out with the impression that mothers of regular children tend to set limits in a gradual way, by using tools of explanations, negotiations, reasoning and demanding; if one tool does not work, then the mother could gradually resort to what may seem to her a more effective tool. These mothers pointed out that conflicts are positive and healthy to their relations with their child, where the mother could use the conflict to clarify the acceptable rules of behaviour. Mothers of avoidant children, however, set immediate limits that were appropriate to the situation, and have propensity to outburst without explanation. The mothers resolved their interpersonal conflict with their child only when "they are the winners". The general expression that they made throughout the interview is that there is no room for compromises and they cannot allow being perceived as weak in front of her child. They express only negative feelings and show a high degree of anger. Researches show that parents' perception of being too authoritarian is significantly associated with high rates of social anxiety among the children.

The fifth scrutiny aimed at examining the impacts of mothers' practice of encouraging achievement. This test show that mothers of regular children attribute less importance to specific educational achievements that are less important to increasing their child's happiness. They encourage their child to equally succeed in both the social and educational fields. Mothers of avoidant children, in contrast, tended to be more authoritarian, while emphasizing the importance of educational achievements in order for their child to succeed in the future. These mothers attribute less importance to success in other non-educational areas; they claim that it is less important to invest in the social spheres or in the sense of autonomy of the child. The findings of one study indicate a relationship between a child's propensity to experience anxiety and the child's exposure to situations resulting from parental outburst responses, such as punishment, physical punishment, criticism and lack of appreciation (Spielberger \& Vagg, 1995). 
Differences were also found in mothers' description of their child. Mothers of regular children indicate only positive traits, compared with mothers of socially avoidant children that stress negative traits. In terms of mothers' assessment of the social abilities of their child it was found that mothers of regular children assess their child as having high potential capabilities compared to mothers of children who are socially avoiding that evaluated their child as having limited to low capabilities.

Similarities between the answers given to this research by mothers in both groups must also be mentioned. In the parameter of terms of conflict's impact on the mother - child relationship, the two groups noted that the conflict did not affect the relationship and were transient. The parameter 'encouragement of autonomy versus overprotection' indicate that both mothers allowed their child to experience independent activity even when there is no guarantee of its success, as long as it does not involve risk; they indicate that they prepare the child and give him an explanation before experience.

\section{Conclusion}

A practical outcome of this study was to provide additional tools, based on the narrow scope of the present survey, for the better and easier recognition and evaluation of potential children at risk in the realm of social avoidant disorder. By focusing on both regular and socially-avoidant disorder affecting youngsters living in similar socioeconomic conditions, geographical settings and families, this research has brought into the fore both sides of a compact and unified sample.

Avoidant identity disorder can be conceptualized as a reflection of high degree of shyness and anxiety that is highly affected parental neglect. The risk factors from childhood abuse and their parent's neglect create real impact on the advancement of avoidant personality disorder. The findings of this study show that a high degree of parental neglect, such as lower care, which increases the likelihood of avoidant personality disorder. The study also demonstrate that with expanding dimensions of child abuse, such as abrupt outburst by the parent, also increase the likelihood of avoidant personality disorder.

The study should be followed by extensive future research focusing on a variety of populations and aspects relevant to the complaint of avoidant personality disorder among school children. By adding variables to the study a larger image of the malady will become clear. Possible criteria not yet adequately researched include: child's gender and avoidant personality disorder, the child's rank within the family, age of each of the parents, and the impact of culture, such as the degree of religiosity of the parents.

The combined effect of several causes could equally contribute toward a clearer picture of the social avoidance conditions. More evidence and better processed data will enable parents and social therapists to detect children at risk and devise appropriate interventions at the personal as well as the family level and prevent the condition from developing. 


\section{References}

American-Psychiatric-Association. (2013). Diagnostic and statistical manual of mental disorders (DSM-5®): American Psychiatric Publications.

Bögels, S., Alden, L., Beidel, D., Lee, A. C., Pine, D., Stein, M., \& Voncken, M. (2010). Social anxiety disorder: questions and answers for the DSM-V. Depression and Anxiety, 27(2), 168-189.

Brennan, K., \& Shaver, P. (1998). Attachment styles and personality disorders: Their connections to each other and to parental divorce, parental death, and perceptions of parental caregiving. Journal of Personality, 66(5), 835-878.

Cramer, P. (2011). Young adult narcissism: A 20 year longitudinal study of the contribution of parenting styles, preschool precursors of narcissism, and denial. Journal of Research in Personality, 45(1), 19-28.

Fletcher, A.C., Walls, J.K., Cook, E.C., Madison, K.J., \& Bridges, T.H. (2008). Parenting style as a moderator of associations between maternal disciplinary strategies and child well-being. Journal of Family Issues, 29(12), 1724-1744.

Hawley, P. (1999). The ontogenesis of social dominance: A strategy-based evolutionary perspective. Developmental Review, 19(1), 97-132.

Herren, C., In-Albon, T., \& Schneider, S. (2013). Beliefs regarding child anxiety and parenting competence in parents of children with separation anxiety disorder. Journal of Behavior Therapy and Experimental Psychiatry, 44(1), 53-60.

Holt, C.S., Heimberg, R.G., \& Hope, D.A. (1992). Avoidant personality disorder and the generalized subtype of social phobia. Journal of Abnormal Psychology, 101(2), 318.

Hudson, J.L., \& Rapee, R.M. (2001). Parent-child interactions and anxiety disorders: An observational study. Behaviour Research and Therapy, 39(12), 1411-1427.

Hughes, S.O., Power, T.G., Fisher, J.O., Mueller, S., \& Nicklas, T.A. (2005). Revisiting a neglected construct: parenting styles in a child-feeding context. Appetite, 44, (1), 83-92.

Joyce, P.R., McKenzie, J.M., Luty, S.E., Mulder, R.T., Carter, J.D., Sullivan, P.F., \& Cloninger, C.R. (2003). Temperament, childhood environment and psychopathology as risk factors for avoidant and borderline personality disorders. Australian \& New Zealand Journal of Psychiatry, 37(6), 756-764.

Kashdan, T.B., Goodman, F.R., Machell, K.A., Kleiman, E.M., Monfort, S.S., Ciarrochi, J., \& Nezlek, J.B. (2014). A contextual approach to experiential avoidance and social anxiety: Evidence from an experimental interaction and daily interactions of people with social anxiety disorder. Emotion, 14(4), 769.

Martínez, I., \& García, J.F. (2007). Impact of parenting styles on adolescents's self-esteem and internalization of values in Spain. The Spanish Journal of Psychology, 10(2), 338-348.

Mayseless, O., \& Scharf, M. (2003). From authoritative parenting practices to an authoritarian context: Exploring the person - environment fit. Journal of Research on Adolescence, 13(4), 427-456.

Moore, P.S., Whaley, S.E., \& Sigman, M. (2004). Interactions between mothers and children: impacts of maternal and child anxiety. Journal of Abnormal Psychology, 113(3), 471-486. 
Muris, P., \& Ollendick, T.H. (2015). Children who are anxious in silence: a review on selective mutism, the new anxiety disorder in DSM-5. Clinical Child and Family Psychology Review, 18(2), 151-169.

Ollendick, T., \& Grills, A. (2016). Perceived control, family environment, and the etiology of child anxiety-revisited. Behavior Therapy, 47(5), 633-642.

Schneier, F.R., Rodebaugh, T.L., Blanco, C., Lewin, H., \& Liebowitz, M.R. (2011). Fear and avoidance of eye contact in social anxiety disorder. Comprehensive Psychiatry, 52(1), 81-87.

Spielberger, C.D., \& Vagg, P.R. (1995). Test anxiety: Theory, assessment, and treatment: Taylor \& Francis.

Turner, S.M., Beidel, D.C., \& Townsley, R.M. (1992). Social phobia: a comparison of specific and generalized subtypes and avoidant personality disorder. Journal of Abnormal Psychology, 101(2), 326. 